\title{
Using Word Games to Improve Vocabulary Retention in Middle School EFL Classes
}

\author{
Nguyen Ngoc Vu ${ }^{1 *}$, Phan Thi My Linh ${ }^{2}$, Nguyen Thi Hong Lien ${ }^{1}$, Nguyen Thi \\ Thu $\operatorname{Van}^{3}$ \\ ${ }^{1}$ Hoa Sen University, 8 Nguyen Van Trang District 1, Ho Chi Minh City, Vietnam \\ ${ }^{2}$ Mynah Education Vietnam, Block C An Loc apartment, Nguyen Oanh street Ward 17 Go Vap District HCMC \\ ${ }^{3}$ Sai Gon University, 273 An Duong Vuong District 5, Ho Chi Minh city, Vietnam \\ *Corresponding author. Email: vu.nguyenngoc@hoasen.edu.vn
}

\begin{abstract}
Vocabulary learning is one of the most challenging aspects of learning a foreign language, especially vocabulary retention at the beginner level. There are currently a number of lexical instruction strategies available, but their use in the Vietnamese EFL context is still limited. Therefore, the appropriateness and efficacy of incorporating word games into English lexical instruction at a middle school in South Vietnam were investigated in this report. Mixed method research was conducted on two classes in grade 7 for eight weeks in order to measure the efficacy of using games in the selected school. Two classes (experimental and control) with 64 students whose English proficiency is more or less the same based on preliminary test scores learned the same vocabulary lessons - the formerly used games to learn vocabulary, while the latter used the conventional approach. Pretests, posttests, questionnaires, and interviews were used to collect the data. The experimental group's increase in vocabulary retention was statistically better than the other in the post-test findings after eight weeks of treatment. Furthermore, qualitative analysis revealed that the experimental group participants found word games to be inspiring, fun, and efficient. This paper concludes that using games to teach vocabulary has proven to be a viable method for English teaching and learning in middle school EFL classes. Learners had more chances to be exposed to the target language in a fun and comfortable learning atmosphere by playing word games and improved their ability to acquire and maintain vocabulary.
\end{abstract}

Keywords: Word Game, Vocabulary Retention, Constructivism, Middle School EFL Classes.

\section{INTRODUCTION}

There are various lexical guidance techniques available, but their use in the context of a non-English speaking environment and crowded classrooms in Vietnam is still limited, especially in general public education. The persistence of the old teaching tradition of the grammar-translation approach, which appears to be unable to train language learners for communicative ability, is in line with these investigations. "If language structure is the skeleton, then vocabulary is the vital organs and flesh," says the author [1]. Thus, vocabulary teaching and learning is critical, especially for beginning learners who are reported to have difficulty recalling new words in a non-English speaking environment where learners have little opportunity to practice their newly acquired vocabulary outside of training and learning to communicate in a foreign language in a formal setting is challenging for many learners [2].

Finding effective methods to assist students in collecting, using, storing, and retrieving words in longterm memory is critical for these purposes [3-5]. Learners have a reason to use vocabulary when they play games. However, the situation in Vietnam differs from that in other nations. It is uncertain whether or not using games is feasible in the chosen school setting and how effective games are on vocabulary acquisition and retention among middle school students. Further experimental research is needed to provide practical guidance. As a result, this study attempts to address the following questions with an emphasis on word games for promoting vocabulary retention with EFL students in Vietnam: 
a. To what extent do word games enhance students' vocabulary retention?

b. What are the students' perceptions of the use of word games for learning vocabulary?

Theoretically, this study contributes to the increasing demand for literature sources of strategies for pedagogical applications to develop students' linguistic abilities by investigating the use of games in language teaching and learning in low resource conditions. In practice, English teachers would benefit from identifying ways to enhance English language teaching in general education, especially at the lower secondary level in Vietnam. The goal of the study is to give them a better understanding of a variety of activities, such as games, in language teaching and learning. This also aids in debating some teachers' views on the impracticality of implementing novel strategies such as word games in Vietnam's public schools. Furthermore, this research may help the school management understand how to encourage school teachers to use teaching methods that meet the communicative needs of their students in the public sector, which is currently constrained by its existing learning evaluation framework.

\section{LITERATURE REVIEW}

\subsection{Game and constructivism}

It was Piaget [6], while researching cognitive development and learning theories as part of his "genetic epistemology," who coined the term "education games." While observing the children in his experiments, he developed a theory of learning and an educational method known as "constructivism," which emphasizes discovery learning over teacherprovided knowledge. In other words, learners are active participants who intervene in their learning to form their own information rather than passively receiving knowledge from the instructor. Teachers are no longer lecturers but facilitators whose function is to assist students during the teaching and learning process. According to Piaget, "accommodation and assimilation" are the two main components in the creation of an individual's new knowledge, and each of them is used in games. Assimilation is the process of connecting old and new information in order to help a person shape and gain new perspectives. Accommodation, on the other hand, is the process of reframing the environment and new experiences into existing mental capacity.

Piaget described games in particular as "the assimilation of stimuli from the outside world and their integration into the adaptation system." According to him, games can be used for a variety of purposes and are an ideal vehicle for children to learn because they learn more efficiently through play rather than guidance [7]. It's worth noting that Piaget only mentioned games in terms of their effect on children's growth. However, in today's evolving educational system, games can be successful for all age groups if they are carefully chosen according to the developmental stage of the learner [8,9].

Educational perspectives see games as activities that allow students to reinforce previous knowledge by repeating it in a more relaxed setting, similar to Piaget's concept of games $[10,11]$. In this light, the importance of "repetition of previous experience in a more relaxed setting" is emphasized, implying that learning in a less stressful or stress-free environment plays an important role in the language learning process. Games are "simple illustrations of language usage and the behavior through which the language is woven" from a linguistic standpoint $[12,13]$. There are several different types of games, each of which focuses on a different aspect of language or ability. Games for language learning are divided into seven categories, according to McCallum [14]: vocabulary games, spelling games, number games, conversation games, structure games, writing games, role-playing, and drama. As previously stated, the aim of this research is to look at ways to improve lower secondary students' lexical retention abilities, so vocabulary games, also known as word games, were chosen for this study.

\subsection{Roles of games in language teaching and learning}

When it comes to the role of games in English language teaching, Plass et al. [15] argue that games will help students become more independent in their language use. Games, without a doubt, can help with this because they have some beneficial characteristics for language learners.

To begin with, according to Faria [16], games can involve all students in the learning process, especially shy students who are hesitant to speak the target language in front of a large audience. When playing games in pairs or groups, however, each learner must interact with one another in order to solve the problem. When given genuine reasons to interact in the target language, these students would feel more at ease than if they were speaking in front of the entire class. Joining together in the game often allows learners to understand and acknowledge the efforts of others, which aids in the development of team-building skills. Furthermore, through several repetitions when playing with various individual students in the language class, playing games helps language learners remember and maintain new vocabulary in their long-term memory 
$[8,17]$. Listening and observing alone, according to [18], does not promote active language stages in learners but rather language knowledge. Learners need chances to use their language in order to progress from language comprehension to language communicative results, and word games have been shown to be effective in ensuring learners' active participation in the learning process. Finally, in addition to providing learners with a plausible opportunity to use and practice the target language $[4,19]$, games provide a great deal of fun and enjoyment, which are essential aspects of language learning that are often overlooked by teachers in their search for teaching points or by course designers [20]. Although the conscious mind is focused on the "task" of playing the game, games help students concentrate their subconscious minds on language processing. As a result, games can help to reduce anxiety, inspire students in second language classes, and increase the likelihood of feedback acquisition [3,9].

In a nutshell, games assist all students in engaging in communicative, constructive, and problem-solving practices that are student-centered. Games provide learners with a rich, meaningful exposure to comprehensible language input while also engaging them cognitively in language use, which is thought to be a prerequisite for language acquisition [21]. Games are, therefore, "part of a teacher's equipment, not only for the language practice they provide but also for the therapeutic effect they have" [1].

\subsection{Benefits of word games in language teaching}

Learning a word, according to Nation [22], is a multi-faceted operation. Different exercises that concentrate on helping learners develop and use words in various ways should be included in order to learn and maintain new words effectively. Most language teaching experts believe that playing word games will help language learners learn vocabulary. In a variety of ways, games have been shown to benefit the learning of vocabulary.

To begin with, games appear to be successful in providing learners with motivation in language learning, especially for young language learners aged 4 to 12 , who typically view games as a key motivator for their learning [12]. Eryilmaz [23] proved this in a study he conducted in a Turkish primary school in 2008. According to the findings of this study, using games created a motivating and enjoyable learning atmosphere, and as a result, students participated more actively in classroom activities, allowing them to learn and retain language more easily and permanently. Students can have to repeat the same questions or words many times when playing games. This gave them the ability to drill and repeat lexical or grammar items in the same way as they would in a traditional classroom, but through playing games, they were able to learn English in a more enjoyable and fun environment through communicative practices. According to Eryilmaz [23], playing games not only allows students to practice their English but also connects them to the real-world application of the language outside of the classroom. Pratolo and Solikhati [24] found that games could pique students' interest in teaching materials and help them learn more in another study conducted in an Indonesian grade 3 classroom.

Apart from the learning inspiration that word games provide, word games appeared to be good tools for enhancing the ability to remember and infer meanings of new vocabulary in the sense of English teaching as a foreign language in a recent study conducted in secondary schools in Turkey and Iran with participants of similar ages to those in the current study [25]. Yalcin and Ozturk [25] used a series of word games (crossword puzzles, charades, twenty questions, passwords, and definition games) to teach a female group of third-grade junior high school students at a private school in this experimental study. The use of these games has been shown to improve learners' vocabulary growth. They provided plenty of opportunities for learners to understand and use new words, which improved their ability to remember and infer meanings. As a result, learners' understanding improved, and they were able to communicate more effectively.

Games in general, and word games in particular, have been shown to be effective in providing adult students with opportunities to meet and discover new vocabulary while also reinforcing previous skills without requiring too much direct teacher assistance. Ghahraman and Shabani [26] proved this when they conducted a study in Iran on the use of word-search puzzles to improve vocabulary skills in intermediate EFL (English as a foreign language) schools. Other studies, such as those conducted by Khan et al. [27] and Plass et al. [15], concluded that games appeared to be successful in improving vocabulary learning, especially retention. These researchers, however, did not provide a good explanation for how successful word games were in achieving these positive results. According to Subhash and Cudney [28], the use of games in the classroom may not be the only reason for such a result. Since the time they spent working on the words was normally marginally longer than when other methods were used by different classes, his experimental students received better results than the others. Word games, on the other hand, were suggested by Faria [16] as a means of increasing students' enthusiasm, which contributed to greater 
interest in teaching material and, as a result, better outcomes.

In the Vietnamese context of English teaching and learning, there has been a shift to "more communicative activities" in the English classroom. However, it is only available at a few large universities and international language centers. The use of creative teaching methodologies that include a variety of communicative activities, especially games, is still uncommon in the public sector, particularly in low resource middle schools, where it is thought that both teacher awareness and school facilities for implementing such methods are lacking [29]. Although some researchers have looked into the teaching and learning of English in Vietnamese high schools and universities, "a limited body of literature published locally in Vietnam shows that study is not a feasible activity among Vietnamese English teachers" [30]. There have been very few studies on the use of games in English teaching in Vietnam. In particular, Huyen and Nga [31] discovered that games were both enjoyable and useful in improving students' communicative competence by providing lots of exposure to the target language. In addition, "lack of cooperation among class members" and "preference for using learner's mother tongue" were listed as roadblocks to expanding the effectiveness of language learning through games. This study was conducted over a two-week span, during which they attempted to incorporate as many games as possible into their adult classes. As a consequence, if the study had been done with adolescents over a longer period of time, the outcome may have been different.

To summarize, the majority of studies in this field appeared to conclude that games in general, and word games in particular, could be used as a useful strategy at all educational levels to reinforce and improve students' vocabulary skills in a variety of language teaching and learning contexts where English is a second or foreign language. In a more communicative and fun language teaching and learning environment, games have also been shown to be inspiring and efficient in helping learners increase vocabulary exposure and providing practical practice of drilling and repeating both lexical and grammar structures. In this way, it aided learners in quickly acquiring and remembering new information, especially vocabulary retention. These findings apply not only to the English language but to every other foreign language. However, reviews have sometimes recorded mixed findings of the efficacy of games for training, and several studies have been performed in a relatively short period of time. If the experiment is carried out for a longer period of time, the findings could be more accurate.

\subsection{Challenges of using word games in English teaching and learning}

Most studies have shown that using games as an instructional strategy in language teaching, especially when it comes to vocabulary, has positive results when compared to other vocabulary teaching methods $[8,32,33]$. However, not all word games are useful in the teaching and learning of languages. As a result, the effectiveness of using games in language teaching is highly dependent on the teacher's choice of suitable games. It can take longer to choose or build the best games for the lesson language instructors want to teach than it does to prepare a typical vocabulary lesson. Because of this, Bafadal and Humaira [33] had mixed results while using games in language teaching at the university level. The findings revealed that word games were both inspiring and effective; however, some students did not participate enthusiastically in the games because the material being examined did not align with their interests. If games are not related to any teaching function, they will be a waste of time.

Another impediment to the use of games in language teaching and learning is their examinationbased orientation [8]. These researchers stated that some participants in their study, including both teachers and students, overlooked the advantages of games because they were more concerned with passing exams than with the necessity of language usage that games offered. Stavy et al. [12] added that "crowded classroom setting and heavy load of the curriculum" stopped teachers from incorporating games into language classes in another study conducted in Turkey. Since games are enjoyable and involve a lot of relaxed and casual contact between students and teachers, they can be perceived as unproductive busywork by some teachers and even students [9]. Apart from that, there are some other issues that arise when students are working in pairs or groups, such as students in monolingual groups tending to speak their mother tongue rather than the target language, less involvement from some students due to their limited strategic competence, shyness, or failure to understand the task's intent $[14,34,35]$.

\section{METHODOLOGY}

The mixed-method quasi-experimental design was used in this research in order to obtain more accurate results and to provide a more thorough and systematic image of what was studied in an educational context. The research was carried out at Cai Be junior high school in the Cai Be district of Vietnam's Tien Giang province. It is one of the largest schools in Cai Be district, with 39 classes, including nine Grade 9 classes, ten Grade 8 classes, ten Grade 7 
classes, and ten Grade 6 classes. Each class has between 35 and 40 students in it. In terms of English, all of the students in this school use the same English textbooks, which were created by the MOET.

\subsection{Research site and research sample}

Two classes from Cai Be middle school's Grade 7 participated in the research. Students had already completed the first test on measuring learning efficiency when the experiment began in week four of the first semester. Two classes with identical average scores were selected to participate in this experiment based on the results of this English test for all ten classes in Grade 7 at Caibe secondary school. The experiment group was chosen at random, and the control group was chosen at random. After one year of learning English in Grade 6, the seventh graders were selected because they were able to read short dialogues and understand classroom instructions. Furthermore, it was more convenient for the researchers to conduct this study without the possibility of test pressure in the MOET-designed school curriculum. Since they were university classmates, both classes were taught by two different teachers who were expected to be identical in age and English history. The gender and English levels of the two groups are described in detail below, based on the first test results.

Table 1.

Demographic information of the research participants

\begin{tabular}{lcccccc}
\hline \multirow{2}{*}{ Group } & \multicolumn{3}{c}{ Male } & & \multicolumn{3}{c}{ Female } & Total \\
& $n$ & $\%$ & & $n$ & $\%$ & \\
\cline { 2 - 3 } \cline { 5 - 6 } Experiment & 14 & $44 \%$ & & 18 & $56 \%$ & 32 \\
Control & 18 & $56 \%$ & & 14 & $44 \%$ & 32 \\
\hline
\end{tabular}

As illustrated in Table 1, the number of students in both groups is equal to 32 students. However, the proportions of males in the control class slightly dominate the experimental one with $56 \%$ and $44 \%$, respectively, while female students in the experimental class surpass that of the other group (56\% and $44 \%$ in the experimental class and in the control class, respectively).

\subsection{Research Instruments}

\subsubsection{Pre-tests and Post-tests}

The pre-test consists of 40 test items based on the MOET- designed English 7 from unit 3 to unit 7. Both the control and experimental groups were given 40 minutes to complete the task. The posttest consisted of a study of the words learned during the experimental teaching, allowing the researchers to compare the effectiveness of the two treatments on the two groups' vocabulary learning. The style of the post-test was the same as the pre-test. The teachers who taught both the experimental and control groups scored both of the exams.

\subsubsection{Questionnaires}

A Likert scale structured questionnaire was used in conjunction with experimental teaching treatment to explore students' perceptions. There are three parts in the survey. The first segment consists of four questions that concentrate on the personal details of respondents. Its aim is to see if there's a connection between a student's academic performance and their educational background. The aim of the second section was to gather student feedback on the importance of vocabulary and whether or not they want to devote more time to vocabulary learning. The following segment contains six questions aimed at determining what challenges learners face when learning new vocabulary. The final segment, which includes seven questions, seeks to elicit feedback from students about how games have been used to teach vocabulary.

Essentially, the overall design of the questionnaire consisted of two types of questions: five Likert scales and alternative-answer questions, which required students to choose from a list of potential responses. Furthermore, the questionnaire was peercorrected and discussed by two English teachers to ensure the accuracy of word selection so that all participants could read and clearly understand all of the objects. The questionnaire was updated twice based on their feedback, then translated into Vietnamese and distributed to all students in the experimental community at the conclusion of the teaching treatment. Many of the questions were answered in class while the class instructor was present.

\subsubsection{Interviews}

A semi-structured interview with eight openended questions was conducted with 12 students from the experimental community. These interviews were audio-taped with the interviewees' consent to ensure a smooth flow of conversation and to avoid missing or forgetting important details. The responses from these will provide us with some insight into students' perceptions of learning vocabulary through word games. Furthermore, these interviews will aid in the triangulation of the data gathered.

\section{RESULTS AND DISCUSSION}

\subsection{Pre-tests results}

All seventh graders in the chosen school were required to use the same textbooks, Tieng Anh 7, 
created by the Vietnamese MOET. There were no advanced English classes in this public school. In each class, the number of good and less-than-good students was equal. A comparison of these values using the independent $\mathrm{T}$-test of the two group means helped us figure out whether or not there was any statistically meaningful difference between the two classes based on the first English standard survey test scores at the beginning of the school year, and it was outlined in Table 2 below.

Table 2 Summary of Descriptive Statistics for Pre-test

\begin{tabular}{lcccccc}
\hline Group & Number & Mean & SD & T & Df & Sig.(2-taied) \\
\hline Experiment & 32 & 2.312 & .8304 & .262 & 62 & .795 \\
Control & 32 & 2.266 & .5818 & & & \\
& & & & & &
\end{tabular}

Table 2 shows that both the experimental and control groups' pre-test average scores were very modest, at 2.31 and 2.27, respectively. Since the two standard deviations as well as the mean values were approximately identical, the students in these two classes may be at the same level of lexical understanding, according to descriptive figures from Table 2. The difference between the two means of the pre-test score between the two groups: experimental and control, was just 0.04 points. However, an Independent samples T-test was used to see whether this difference could lead to some statistical significance. Clearly, the obtained $t$ value: $t(62)=.262$ and $\mathrm{p}=.795$ is greater than the set level of 0.05 , implying that the disparity between the two means did not result in a statistically significant difference at the chosen confidence level.05 for a two-tailed test. In terms of vocabulary skills, the two classes may be said to be compatible.

\subsection{Post-tests results}

The posttest was carried out after eight weeks of using word games in English teaching, and the scores of students in two classes were checked and shown in Figure 1 below.

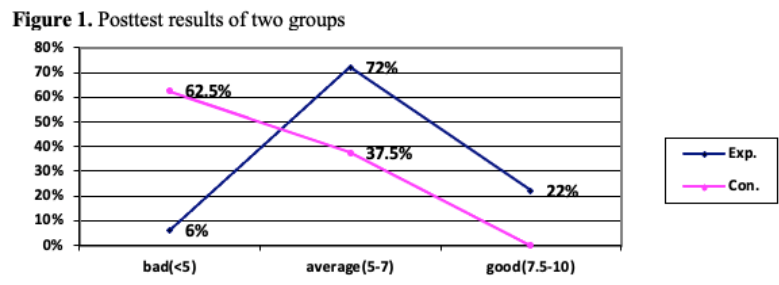

Students in the experimental class outperformed their counterparts in the control class in the posttest performance, with a mean score of 6.375 versus 3.875 , as shown in Figure 1. The number of students in the control group who received a score of less than 5 was significantly higher than that of the study participants, with 62.5 percent and $6 \%$, respectively. Furthermore, the percentages of treatment-group students who received average and good scores are 72 percent and 22 percent, respectively, while the control group students received 37.5 percent of the average score and no one received a good score.

As previously mentioned, the experimental students appeared to do better in lexical achievement following the intervention of games. However, a repeated calculation test was used to determine whether or not this difference was statistically significant. The significance level for this test was set at 0.05 . The results of this test are shown in Table 3 below.

Table 3: Summary of Repeated measures for Tests of Within-Subjects Contrasts

\begin{tabular}{lcccc}
\hline & F & Df & sig. & Partial Eta \\
\hline Time(Pre \& Post) & $23.429^{\mathrm{a}}$ & 1 & .000 & .278 \\
time * first_test_score & $1.618^{\mathrm{a}}$ & 1 & .208 & .026 \\
time $^{*}$ Group & $41.227^{\mathrm{a}}$ & 1 & .000 & .403 \\
\hline
\end{tabular}

Exact statistic

b. Design: Intercept + first test score + Group

Table 3 revealed that using games had a significant impact on students' results, with statistical values of $\mathrm{F}=23.429, \mathrm{P}=.000$. There was an important key contrast for time, indicating that the pre-test and posttest means were statistically different. Furthermore, since $\mathrm{P}=.208$ is greater than the set confidence level of .05, there was no substantial difference in time and first-test ranking. Inferentially, the gap between the means of the pre and posttests was unaffected by the first test score. Students in both the control and experimental groups improved their lexical stock. Figure 2 depicts the change in the means of the pretests and post-tests for each group.

Figure 2. The change in pre-and post-test means for each group

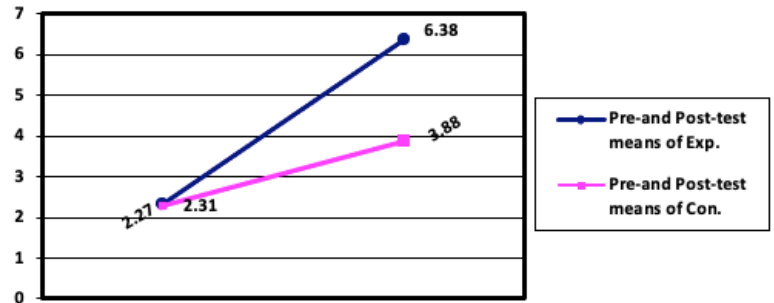

As shown in Figure 2, the control group's mean increased slightly from 2.27 before the test to 3.88 after the test. Meanwhile, the experimental group's post-test mean increased from a slightly poor value of 2.31 to a rather good value of 6.38. The most interesting finding is that there is a significant association effect between time (pre and post-tests) and group (experimental and control groups) with $\mathrm{F}=$ 41.227, $\mathrm{P}=.000$. In other words, as a result of the 
procedure, there was a statistically important difference in the means of the two classes for pre and post-tests. With the same amount of time spent playing games, the experimental group's lexical stock increased significantly more than the control group's.

\subsection{Questionnaire}

The majority of the students, accounting for 88 percent of the experimental participants, agreed on the value of vocabulary in learning a foreign language. Eighty-four percent of respondents thought their lexical stock was average to poor, and 75 percent wished to devote more time to improving their lexical stock. The graphs below show how the experimental students felt about the importance of vocabulary in foreign language learning.

Figure 3: Learning vocabulary is important in learning a foreign language

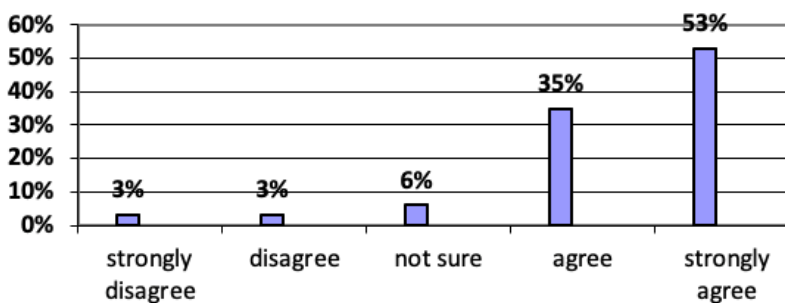

Figure 4 showed that the majority of students, up to 88 percent of the experimental participants, agreed on the role of vocabulary in foreign language learning. Just $6 \%$ of students disagree with this assertion, and another $6 \%$ are unsure about the value of vocabulary. All of the teachers consulted agreed that vocabulary plays an important role in English teaching and learning. They did not, however, teach vocabulary as a separate ability but rather as an integral part of four other skills: listening, speaking, reading, and writing. This seemed to be a positive indication, as virtually all selected foreign language learners were conscious of the value of vocabulary. Nobody may deny the importance of vocabulary in foreign language learning. However, having a strong lexical stock in English does not always imply that learners would be able to communicate effectively in English. Learners need a lot of practice speaking experiences in various ways to be able to use such words. Otherwise, they have only learned the dead vocabulary that was described in the introduction. This might be the case why $43.5 \%$ of the students' responses went against the statement "I can't speak English well because of my limited vocabulary."
Figure 4. I can't speak English well because of my limited vocabulary

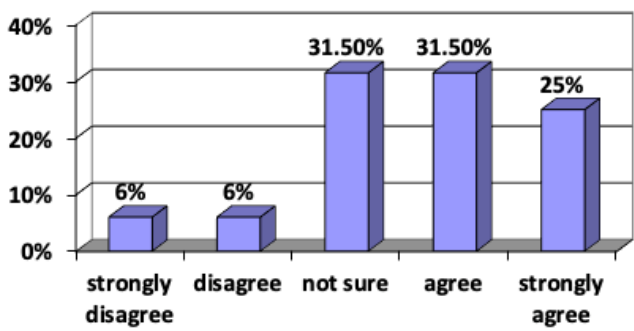

Figure 4 shows that almost half of the participants $(43.5 \%)$ did not admit that they could not speak well due to a lack of vocabulary. When it came to the argument "knowing more vocabulary would boost my English," however, 81.5 percent of the experimental students agreed. Just $6 \%$ of them approved, while the remaining 12.5 percent expressed reservations.

Despite the value of English vocabulary, the students were aware that their current lexical awareness was insufficient. Indeed, the majority of respondents (84\%) thought their lexical stock was average to poor. This assessment of their own English proficiency matched what the researcher discovered in their first and pre-test scores. Knowing the importance of vocabulary in language teaching and learning, $75 \%$ of respondents wanted to spend more time developing their lexical stock, while 19\% were unsure and another $6 \%$ of the experimental students did not want to spend more time on it. Figure 5 depicts a broad overview of these figures.

Figure 5. Students' desire for spending more time on Vocabulary learning

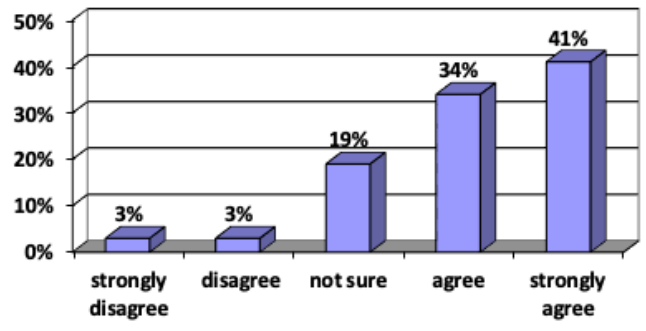

\subsection{Interview}

The most enjoyable aspects of their language learning experience during the experiment were the fun and relaxed atmosphere, as well as the unusual teaching process, which encourages their interest and eagerness to participate in classroom activities. This demonstrated that experimental students wanted to have fun while studying a foreign language, which had significant implications for second language pedagogy. Students with the codes F04, F05, F32, and F28 said they liked almost all of the games because each type has its own characteristics that make the 
classroom more interesting. F32 said: "Thanks to these games, I learn new vocabulary faster compared with the way the teacher taught before." F28 also claimed: "I really look forward to English period to be played English vocabulary games. To tell the truth, I don't really like coming to English class with only copying new words from the board, reading the text, and sitting at my own desk to review new words". It was even more interesting when M21 mentioned: "Using games in English class makes weak student like me want to come to class more often, and I stop cutting class during English periods. Games make class time go faster".

Among the many reasons for their support, 85 percent of the students said that games allow them to study and practice newly learned words, while some of them, 9 percent of the students, are still undecided. The remaining $9 \%$ as opposed to the advantages that games have for learning new words. In detail, F05 said: "Games encourage me to express myself in English. Although I am a little confused when playing these games, I am not afraid to use English, even the wrong one. All I have to do is to help my teammates to be able to guess the right answers to win the games".

Among the many reasons for their support, 85 percent of the students said games allow them to study and practice newly learned words, while some of them, 9 percent of the students, are still undecided. The remaining $9 \%$ do not believe that games provide opportunities for learning new vocabulary. Specifically, F20 and F04 admitted: "I really feel annoyed about some boys' behavior during playing the game named "finding someone who... These boys keep moving to girl's groups to tease us instead of practicing asking some questions in the form as the teacher requested". When incorporating games into a lesson plan, it is important for the instructor to take a close look at the entire class. The teacher must ensure that students obey their directions and make the most of the opportunity to practice speaking English rather than doing anything else.

Learners are getting more chances for language use due to the consensus that games will create a cheerful and relaxed environment in the language class, and 72 percent of the responses considered games as helpful tools in assisting them to remember new words longer and more quickly. However, $22 \%$ of the experimental community were uncertain about this, and only $6 \%$ of the responses disagreed with the assertion that "games help me remember new words longer." This can be explained in part by the fact that all of the experimental participants were unfamiliar with this type of game. Understanding the rules of such games and communicating in English while playing could be difficult for them, and as a result, they considered games ineffective in aiding their learning of new words.

To summarize, a key trend emerged in terms of the game's facilitation of students' vocabulary learning process: students were aware of its value in terms of providing students with more practice opportunities for new words, creating a more exciting classroom atmosphere, and increasing vocabulary retention. Surprisingly, the vast majority of students $(81.5 \%)$ stated that they did not participate in any of the game activities. This creates an interesting paradox: while the learners considered the activity to be beneficial and effective, they also indicated that they did not actively engage in all game activities. The question of whether games are childish or just time-consuming arises. When asked to respond to this issue, nearly all of the people polled $(91 \%)$ said they disagreed with the comment. With 81 percent of the responses, the same negative responses to the feature that "games are only time-consuming because they make the class noisy" were found. This suggests that games were useful in aiding these students' study and learning of new content.

After having asked for their elaboration on the games which they were inclined to, over $90 \%$ of the students were in support of taboo games rather than the others. This game was relatively simple, which aimed to review the old vocabulary they had learned. All the learners had to do was to use other words or phrases to describe the target words. It, therefore, engaged all the class members in the classroom activities in an easy while competitive atmosphere. Evidentially, one student code F26, said: "Playing games like "taboo, cover object" and "alphabets dash" helps us cooperate to find out the solution to the question in a fast way so that our team can win the game. This makes us get closer to each other".

Numerous responses, on the other hand, cast a negative light on games that require a significant amount of time and thought, such as "twenty questions" (10/32), "word search crossword puzzle" (7/32), "network," and "describing image" (7/32). These definitions vary from students' limited vocabulary to the games' dullness as reasons why certain games did not appeal to all students. Nearly $80 \%$ of respondents said they lacked the confidence to engage in certain games because of their limited vocabulary actively and didn't know how to contribute to these new activities. Aside from that, the difficulty and incompatibility of certain games were also deterrents to most of these students participating in the games. However, it was difficult to determine which games were the best and which were the worst in this experiment since some games could be good and appropriate for some students but not for others, 
necessitating more research over a longer period of time to determine.

\section{DISCUSSION}

Previous studies $[9,15,36]$ have found that games can help learners learn and recall material better by "maintaining students' excitement," "creating a comfortable environment," "promoting team learning and collaborative skills," and thus "help learners learn and recall material better."

In line with these results, this study discovered that using games created a motivating, enjoyable learning atmosphere, allowing students to participate more actively in classroom activities, allowing them to learn and gain lexical knowledge more easily. As a result, using games in English classes seemed to be appropriate and relevant in current pedagogical contexts in Vietnamese public schools. Students can have to repeat the same grammar points or vocabulary many times when playing games. This allows for drilling, which is close to what is done in a traditional classroom environment. However, when playing games, such drills and repetitions took place in a more enjoyable learning atmosphere, in the form of communicative and competitive sports, as demanded by the Vietnamese Ministry of Education in its quest for ways to enhance English teaching and learning.

Furthermore, most of the experimental participants agreed that playing games in language class were beneficial in bringing class members closer together by requiring cooperative work to find answers to questions and developing mental activity. These elements are needed to bring students closer to the "round growth" of children in today's educational settings. In terms of a variety of activities aimed at increasing exposure to target vocabulary, games in general, and word games in particular, are helpful to language learners in terms of a variety of activities aimed at increasing exposure to target vocabulary [37]. Many of these are said to excite students in language classes, making it easier to achieve the teaching goal [12]. In this light, during the eight weeks of the experiment, the current study carefully tried to apply a collection of ten games that have been suggested in language teaching pedagogy or successfully implemented in language classes in some previous researches $[8,9,37]$. However, this does not imply that these games are always applicable to all language teachers or that they can produce comparable outcomes in other pedagogical contexts, as the application of such technologies is highly dependent on the contexts in which they are used, including the nature of the individual instructor and learner.
In the Iranian context, "twenty question games" and "crossword puzzles" were found to be particularly useful and appropriate for language learners [26]. However, based on the findings of this study's data analysis in a specific environment, these word games may be enjoyable and successful in helping some language learners learn new words, but they may be embarrassing for others. Some experimental learners considered these two games to be a waste of time, complicated, and tedious because they allowed them to practice asking and answering questions using newly learned words. Others, on the other hand, found them to be a waste of time, complicated, and boring. In this light, we may conclude that language teaching is a complex and often frustrating job, and those language instructors should make a constant effort to consider, create, and form games to meet the needs of teaching and learning target language when incorporating games into the classroom practices.

Except those, another finding from this study was consistent with Lewis's comment about young language learners that "learners at the age between 4 and 12 years of age will not take language learning as the key motivational factor but will take the fun from games as motivation for their learning" [38].

Evidently, from both mentalist and systemic viewpoints, the semantic mapping game is a significant advancement in language teaching in general and vocabulary teaching in particular. Johari et al. [39] claim that the former will "construct active and connective mental processes," while the latter sees semantic mapping as "an organizer to connect nodes to lines". It can aid comprehension in various ways, including assessing learners' readiness to read, preparing them for lexical awareness, instructing them to conceptualize the items representing the subject, and encouraging learners to relate prior knowledge to the new one. With this in mind, the researchers chose semantic mapping activities as a pre-reading task nearly every week in this report. The researchers hoped to provide the students with a detailed overview of the material and the concepts and lexical objects that they might encounter in the reading by showing or asking them to match and extend the maps or network. This will aid in their comprehension and memorization. Other game-like practices, such as crossword puzzles, explaining pictures, and twenty questions games, were also purposefully introduced into the English classroom practice during this experiment to further improve learners' logical thinking and speaking ability. However, these types of activities did not seem to appeal to all of the students because they were viewed as less competitive and enjoyable than other games like "covered object" or "taboo," which were found interesting and competitive to play by the majority of the experimental 
participants. According to student revelations from their interviews, many learners were hesitant to participate in such games because they required a lot of logical thought to solve the tasks. This finding may be explained by the fact that it was conducted in a Confucianism-influenced culture such as Vietnam, especially at the general education level, where learners appeared to be passive receivers of information rather than active interactants who intervene in their learning [40]. Learners in Vietnamese classrooms in general, and English language classes in particular, do not know how to initiate conversation and often sit silently until the teacher calls them to talk individually. Interrupting, questioning, or challenging their instructor would be considered impolite. They even fear being laughed at by their peers if they openly ask the teacher for clarification if they don't understand anything in the lesson. In addition to this learning culture, the old method of formulaic drilling and practice exercises in foreign language classes has led to Vietnamese learners' "passive learning" [4]. Such culturally relevant pedagogical circumstances can clarify, to some degree, why Vietnamese language learners found cognitively scaffolding game-like practices like role plays, problem-solving exercises, and debates or speaking in front of the class odd.

From these two examples, language instructors should consider the culture of their students when choosing games to use in their classrooms, rather than focusing solely on teaching objectives, age, and interest. Short, easy, but competitive games involving the whole class would be ideal for young learners in this particular school setting because they are still too shy.

In considering the limitations of using games in language classes, particularly English teaching and learning in this context, this study discovered the same issues that were mentioned in the section regarding learners' preference for speaking their own mother tongue rather than the target language, the noise it can cause in the language class when playing games, and especially the contradictions that can occur when using games in language classes. These things were thought to be impediments to the use of games in language classroom practice in Vietnamese schools.

Apart from that, the lack of English language proficiency among the majority of the teachers at this school was identified as another barrier to incorporating games into language classes in this report.

It's understandable to come to the drawbacks of using games in language classes. However, implementing these game activities in this school setting was still fresh, and the time was insufficient. It was unavoidable to run into such obstacles. Teachers' English competence is important for building Vietnamese learners' communication skills in public schools. With more confidence in language ability, both teachers and students are more motivated to speak English, and they will be free of the pressure of formal exams. Thanks to this, games and other communicative practices would be generally promoted in English classrooms, and such creative methods would become familiar to both teachers and students.

In summary, despite some issues that arose during the use of games as lexical instruction in classroom practice, this small-scale study found that games are applicable and suitable to English teaching and learning in Vietnamese school contexts, particularly in vocabulary teaching.

\section{CONCLUSION AND RECOMMENDATIONS}

The current study's positive findings suggested that games played an important role in English teaching and learning, especially in the remembrance and retention of new words. This implies that game use should be considered essential to instructional planning informal learning environments.

A number of games in the body of foreign language teaching and learning literature can be used to aid young learners in language learning, including vocabulary recall. If different games are included in language classes, learners would be more inspired [41]. The current study has released ten games with very specific instructions on when and how to use them, as well as how to tailor them to the learner's level. Language teachers, on the other hand, should be cautious when choosing games to use in their classes. It is recommended that the instructor first concentrate on words that are extremely important for student's comprehension of the text and are commonly used in real life, and then choose games after taking into account the students' nature and cultural background in terms of learning patterns, pacing, classroom environments, learners' proficiency level, needs, and interests. Complex or time-consuming games may not appeal to many young and beginning language learners, particularly those who are already struggling with their new language. Instead, some easy and competitive game-like activities may be more appealing. Language teachers should simplify the games in such situations. Language teachers can, for example, reduce the number of detractors in word search puzzle games by encouraging students to use phrases rather than complete sentences, which can be difficult for such students. 
Furthermore, the most challenging aspects of learning English vocabulary for Vietnamese learners in this study were word structure and pronunciation. As a result, games that need a lot of practice in these two fields are also recommended. Apart from that, language teachers should clearly clarify the goals and rules of vocabulary games to students in order to get the most out of them. Before students participate in group work, they should be given clear instruction. This allows learners to concentrate more on the teacher's expected learning outcomes and eliminates the notion that playing games are a waste of time. Students can engage more and gain more in their vocabulary learning if they are mindful of the activity's educational benefits. Finally, English teachers must keep a close eye on the entire class. During the application of game-like activities, going around the classroom as a facilitator and consultant to help learners concentrate on the setting target is necessary.

\section{AUTHORS' CONTRIBUTIONS}

Nguyen Ngoc Vu, Phan Thi My Linh, Nguyen Thi Hong Lien, Nguyen Thi Thu Van conceived and planned the experiments. Phan Thi My Linh and Nguyen Thi Hong Lien carried out the experiment. Nguyen Ngoc Vu, Nguyen Thi Thu Van took the lead in writing the manuscript. All authors provided critical feedback and helped shape the research, analysis, and manuscript.

\section{ACKNOWLEDGMENTS}

This research was partially supported by Hoa Sen University and Sai Gon University. We thank our colleagues from the two universities for insights and expertise that assisted the research, although they may not agree with all of the interpretations of this paper.

\section{REFERENCES}

[1]. T. Hedge, The Practice of English Language Teaching, ELT J. 57 (4) (2003) 401-405.

[2]. S. Lee, Raising EFL Learners' Awareness of L2 Lexical Errors and Correct Usage: A Dual Coding Approach, English Teach. 72 (2) (2017) 29-50.

[3]. E. Gozcu and C.K. Caganaga, The importance of using games in EFL classrooms, Cypriot $J$. Educ. Sci. 11 (3) (2016) 126.

[4]. B.P. Hung, V. Truong, and N.V. Nguyen, Students' responses to CL-based teaching of English prepositions, Egit. Arastirmalari Eurasian J. Educ. Res. 2018 (73) (2018) 4158.
[5]. N.N. Vu, Cognitive Processing of English Idioms and Implications for Language Teaching, $J$. Sci. HCMC Univ. Educ. 11 (77) (2015) 5158.

[6]. J. Piaget, The child's conception of physical causality, Routledge, New York, (2013).

[7]. J. Piaget, Intellectual evolution from adolescence to adulthood, Hum. Dev. 15 (1) (1972) 1-12.

[8]. L. Yuliawati and A. Aprillia, The Application of Communicative Language Teaching Method in Vocabulary Teaching, Loquen English Stud. J. 12 (2) (2019) 99.

[9]. I.C. Horea, Business English Word Games - a Welcomed Vocabulary Teaching Technique, J. Lang. Specif. Purp. 2 (1) (2015) 7-20.

[10]. O. Saeed and A. Neyadi, The Effects of Using Games to Reinforce Vocabulary Learning, $J$. Appl. Linguist. Lang. Res. 2 (3) (2007) 99107.

[11]. N.N. Vu, Conceptual metaphor about power and respect in English and Vietnamese idioms, $J$. Soc. Sci. HCMC Univ. Educ. 35 (2012) 3-10.

[12]. L.Z.D. Stavy, F. Subon, and N. Union, Using Language Games for Vocabulary Retention in a Rural Primary School in Sarawak, Int. J. Serv. Manag. Sustain. 4 (2) (2020) 101-120.

[13]. H. Lubis, The Effect of Playing Online Vocabulary Games and Motivation on Student's Vocabulary Mastery in Insan Utama Junior High School Pekanbaru, TANJAK J. Educ. Teach. 1 (2) (2020) 87109.

[14]. M. Berman, Word games, ELT J. 34 (3) (1980) 213-215.

[15]. J.L. Plass, B.D. Homer, and C.K. Kinzer, Foundations of Game-Based Learning, Educ. Psychol. 50 (4) (2015) 258-283.

[16]. M. Faria, Word games and molecular recognition - The creative control of endothelial cell function, BioSystems 187 (2020)

[17]. N.N. Vu et al., Effectiveness of Second Life Virtual Learning Environment for Language Training in Hospitality and Tourism, in Proc. 17th Int. Conf. Asia Assoc. Comput. Lang. Learn. (AsiaCALL 2021), Atlantis Press, (2021): pp. 19-28.

[18]. J. Flood, S.B. Heath, and D. Lapp, Handbook of research on teaching literacy through the communicative and visual arts, Oxford 
University Press, Oxford, (2004).

[19]. O.N. Saracho, Handbook of research on the education of young children: Fourth edition, Routledge, New York, (2019).

[20]. J.T. Tang, Comparative study of game-based learning on preschoolers' English vocabulary acquisition in Taiwan, Interact. Learn. Environ. (2020).

[21]. K. Gregson, Teaching Children How to LearnTell it Again! The Storytelling Handbook for Primary English Language Teachers, ELT J. 71 (1) (2017) 113-117.

[22]. P. Nation, How large a vocabulary is needed for reading and listening?, Can. Mod. Lang. Rev. 63 (1) (2006) 59-82.

[23]. M. Eryilmaz, The Effectiveness Of Blended Learning Environments, Contemp. Issues Educ. Res. 8 (4) (2015) 251-256.

[24]. B.W. Pratolo and H.A. Solikhati, The implementation of digital literacy in Indonesian suburban EFL classes, Int. J. Sci. Technol. Res. 9 (1) (2020) 1508-1512.

[25]. O.B. Yalcin and E. Ozturk, The Effects of Digital Storytelling on the Creative Writing Skills of Literature Students Based on their Gender, in Proc. 2nd Int. Conf. Gend. Res. (ICGR 2019), (2019): pp. 59-65.

[26]. V. Ghahraman and M. Shabani, The effects of word games on Iranian elementary EFL learners' vocabulary achievement, Int. J. Lang. Stud. 15 (1) (2021) 123-144.

[27]. A. Khan, F.H. Ahmad, and M.M. Malik, Use of digital game-based learning and gamification in secondary school science: The effect on student engagement, learning and gender difference, Educ. Inf. Technol. 22 (6) (2017) 2767-2804.

[28]. S. Subhash and E.A. Cudney, Gamified learning in higher education: A systematic review of the literature, Comput. Human Behav. 87 (2018) 192-206.

[29]. H.T.M. Nguyen, The EFL Context in Vietnam and East Asia, in Model. Mentor. Lang. Teach. Educ. English Lang. Educ., Springer, Cham, (2017).

[30]. H.H. Pham, Researching the research culture in English language education in Vietnam, TeslEj 10 (2) (2006) 1-20.
[31]. N.T. Huyen and K.T. Nga, Learning Vocabulary through Games: The Effectiveness of Learning Vocabulary Through Games, Asian EFL J. 5 (2003) 1829-1841.

[32]. A.K.. Alghamdi and S. Al Ahmed, Effective Methods for Teaching English Vocabulary to Saudi Female Students, J. Educ. Learn. 12 (1) (2018) 118-125.

[33]. M.F. Bafadal and H. Humaira, The Use of Charades Games in Teaching Vocabulary to the Junior High School Students, Linguist. Elt J. 5 (1) (2019) 14.

[34]. D. Bergström, C. Norberg, and M. Nordlund, "Words are picked up along the way"Swedish EFL teachers' conceptualizations of vocabulary knowledge and learning, Lang. Aware. (2021).

[35]. C.W. Wei et al., The effects of competitive gaming scenarios and personalized assistance strategies on English vocabulary learning, Educ. Technol. Soc. 21 (3) (2018) 146-158.

[36]. H.J.H. Chen, H.L. Hsu, and Z.H. Chen, A study on the effect of adding $\mathrm{L} 1$ glosses in the subtitle of an adventure game for vocabulary learning, Interact. Learn. Environ. (2020).

[37]. H.J.H. Chen et al., Investigating the Impact of Integrating Vocabulary Exercises Into an Adventure Video Game on Second Vocabulary Learning, J. Educ. Comput. Res. 59 (2) (2021) 318-341.

[38]. M. Lewis, On the development of personality, in L.A. Pervin, O.P. John (Eds.), Handb. Personal. Theory Res., Guilford Press, (1999): pp. 327-346.

[39]. A. Johari et al., Interactive English Language Learning: DishZle Language Game, Int. J. Serv. Manag. Sustain. 3 (2) (2020) 1-19.

[40]. N.N. Vu, N.T.T. Van, and N.T.H. Lien, Crosslinguistic Analysis of Metonymic Conceptualization of Personality in English and Vietnamese Idioms Containing " Head ", " Face " and "Eyes," Int. J. English Lang. Stud. 2 (4) (2020) 23-32.

[41]. K.K. McGregor et al., Learning while playing: A randomized trial of serious games as a tool for word mastery, Lang. Speech. Hear. Serv. Sch. 50 (4) (2019) 596-608. 